\title{
Letter to the Secretary of State for Home Affairs
}

\author{
Arden R. Tomison
}

Dear Mr Straw,

I awoke on Monday 19 July to the news that you were publishing a Consultation Paper to explore the possibility of introducing preventive detention for people with severe personality disorders. In your interview on radio that morning you seemed very determined to be sure that such legislation was introduced in the expectation that incarceration of the 200 people with severe personality disorders who would be subject to such detention, would somehow enhance public safety.

I have had an interesting week since. Every patient I have seen has raised the issue with me. The first was a delightful middle-aged woman of good premorbid personality, who suffers from paranoid schizophrenia and who, for many years, was on a Restriction Order of the Mental Health Act, but who has been informal now for a considerable time, has insight into her condition and who is fully adherent to all aspects of her care programme. She talks with wisdom and humour about her condition, managing her life well. She was concerned that the proposed legislation might apply to her. I did what I could to reassure her.

I then wrote to a patient who, in my view, has a severe personality disorder, who came to see me first some five years ago because he was afraid he might act on his violent impulses. We have been in touch since. He is a very regular attender and 1 have done what I can to give him advice and psychotherapy to try to ensure that he felt in control of himself. As far as I am aware, this has been successful so far. This therapeutic relationship was established on an explicit contract that I would do what I could to help, but that he was entirely responsible for his behaviour if he chose to act and, if he did so, no reports from me were likely to keep him out of custody. Further, that if I thought he was about to do something, I would

The College's response is being finalised following consideration by Council in October, and will be avallable on the College's web-site members area (www.rcpsych/members/memfo.htm) by the end of December. be obliged to tell the police. Otherwise everything would be held strictly within medical confidence. He has been anxious that preventive detention might be introduced and has reasonably wondered how it might affect him. I have told him that, if he continues to tell me of his violent fantasies then I will be obliged to disclose them and to make him subject to preventive detention as it seems that your proposal is that $I$, somehow, become responsible for the way he thinks and any behaviour that might flow from that.

In my clinic today I have seen four people. Another one, already diagnosed by a colleague as having a dyssocial personality disorder with concerns about major violence, who was referred to me for a second opinion, did not turn up. I wonder why?

Of the others, one is a man who has had periodic bouts of mental illness, almost certainly drug-induced. He has served a number of terms of imprisonment for a variety of crimes, some including violence. He was reassured that, as far as I understood it, he did not come under the proposed legislation and neither did the man with post-traumatic stress disorder, probably not a personality disorder who, nevertheless, does behave with apparently impulsive violence when minimally provoked.

The other two have, undoubtedly, severe personality disorders. Both have behaved with major aggression and violence in the past and one continues to do so. Both were presented via their general practitioners requesting help and I am doing what I can by way of psychotherapy. advice and medication where indicated. The same therapeutic contract was established with them being clearly told that they were responsible for their behaviour and the matters we discussed were in confidence. That has now changed and neither they, nor I, are sure that our therapeutic relationship is still on the same footing but I have had to prepare both of them for the possibility that they will be made subject to preventive detention at some point in the future. Both of them still want to come and see me at present but have suggested that they will not do so if they think I have to get them 'locked up'.

I expect I will have to repeat similar discussions with everyone else on my case-load. If I am 
to continue practising as at present and take referrals of such individuals from colleagues, then it seems I will become a 'thought policeman' and will have to assume responsibility for any behaviour that might flow from their thoughts. I will have to explain to anyone that is referred the limits of confidentiality, whereupon I would expect a brief interview and the early exit of the proposed patient from the clinic. The easy thing would be for me to cease to take referrals from such quarters and simply deal with referrals of individuals already charged with, or convicted of, offences. Either way some individuals with major problems in controlling violent behaviour will be denied the opportunity to positively address their problems on a voluntary basis. Whether or not this will enhance, or reduce, public safety remains to be seen.

Finally, I estimate that I have already seen the 200 people that you have referred to as being in need of preventive detention. I expect my colleagues have too. I cannot understand where this figure arises from as it is so completely out of line with published epidemiology of personality disorders, both in the community and in institutional settings.

I awaited receipt of your Consultation Paper (Home Office \& Department of Health, 1999) with great trepidation. Having now read it, I remain profoundly uneasy at the potential consequences of your proposals.

Yours sincerely.

\section{Reference}

Home OfFice \& Department of Health (1999) Managing Dangerous People with Severe Personality Disorder. Proposals for Policy Development. London: The Stationery Office.

Arden R. Tomison, Consultant Forensic Psychiatrist, Specialist Forensic Psychiatrist, Fromeside Clinic, Blackberry Hill, Stapleton, Bristol BS16 1ED

\title{
Royal College of Psychiatrists' Faculty of General \& Community Psychiatry and The Collegiate Trainees Committee Joint Annual Meeting
}

\author{
$9^{\text {th }}$ - $10^{\text {th }}$ March 2000, Kensington Town Hall, London
}

Sessions to be held on:

- Community Psychiatry - Psychiatry and Primary Care

- Psychiatry in the A\&E Department - Epidemiological Studies in Psychiatry

- Neuropsychiatry and Neuropharmacology

Also to include:

The Willam Sargant Lecture

'Psychopharmacotherapy in the context of culture and ethnicity'

Professor Keh-Ming Lin, UCLA School of Medicine, NIMH Research Center on the Psychobiology of Ethnicity, USA

If you require further details on the above meeting please contact the Conference Office at The Royal College of Psychiatrists on 01712352351 ext 168, or by fax on 017I 2596507. 